See discussions, stats, and author profiles for this publication at: https://www.researchgate.net/publication/337363074

\title{
¿POR QUÉ SERÁ QUE AQUÍ HAY QUE REPETIR TANTO LAS COSAS? DE LOS PATRIMONIOS PRIVADOS A LOS EMBLEMAS OLVIDADOS EN LA PRODUCCIÓN MONUMENTAL BOGOTANA (1880-1938)
}

Preprint $\cdot$ November 2019

DOI: $10.13140 / R G .2 \cdot 2.18968 .34566$

CITATIONS

READS

0

273

1 author:

Fabián Andrés Llano

Universitaria uniagustiniana

88 PUBLICATIONS 72 CITATIONS

SEE PROFILE

Some of the authors of this publication are also working on these related projects:

Prácticas Pedagógicas y Didácticas View project

TURISMO DE MEMORIA Y POSTCONFLICTO: CULTURAS DEL RECUERDO ALREDEDOR DE LAS TERTULIAS, COMIDAS Y BEBIDAS EN EL OCASO DE LA ATENAS SURAMERICANA (1910-1950) View project 


\section{¿POR QUÉ SERÁ QUE AQUÍ HAY QUE REPETIR TANTO LAS COSAS? DE LOS PATRIMONIOS PRIVADOS A LOS EMBLEMAS OLVIDADOS EN LA PRODUCCIÓN MONUMENTAL BOGOTANA (1880-1938) ${ }^{1}$}

Fabián Andrés Llano. ${ }^{2}$

\section{Resumen}

El siguiente artículo de investigación abre la discusión sobre los monumentos al hacer hincapié en una historia del concepto. La mirada sobre su origen en el occidente cristiano, su relación con la configuración del Estado Nación moderno y las comprensiones sobre su condición de producto cultural, permitió hacer el tránsito hacia la discusión sobre la legitimidad del patrimonio histórico. En el marco teórico el patrimonio histórico se comprendió como elaboración social y espacial y como producto cultural provocado por luchas sociales. La objetivación del patrimonio histórico bogotano, en particular de los monumentos, requirió de un enfoque de historia social como socioanálisis con el propósito de evidenciar las condiciones de su producción. Esta objetivación permitió poner al descubierto la problemática del olvido de los monumentos bogotanos con la especificación de los circuitos de legitimación en el espacio social y urbano bogotano entre 1880 y 1930.

1 Este artículo es producto de la investigación historia social del patrimonio histórico cultural en Bogotá: (1880-1930) financiada por la Corporación Unificada Nacional de Educación Superior CUN, también retoma algunos elementos del libro el héroe, el lujo y la precariedad: patrimonio histórico en Bogotá 1880-1950 Ediciones Grancolombianas, diciembre 2010. La pregunta realizada en el título de este articulo procede de las reflexiones de la artista colombiana Beatriz González a propósito de la intervención de los Columbarios del cementerio central con su obra Auras Anónimas. Esta obra se realizó bajo la representación de fotografías y testimonios que la autora coleccionó y luego convirtió en siluetas. Estas formas sombreadas las denominó los cargueros de la muerte. La pregunta hace alusión, según la artista, a la necesidad de la repetición para que los testimonios se fijen en la memoria, ya que la inmediatez impide crear iconos. Ver la exposición de Beatriz González denominada Desplazamientos en el Museo de Artes Visuales en la Universidad de Bogotá Jorge Tadeo Lozano.

${ }^{2}$ Doctor en Ciencias Humanas del Patrimonio y la Cultura Universidad de Girona (España) Magister en Investigación social interdisciplinaria de la Universidad Distrital Francisco José de Caldas, Licenciado en Ciencias Sociales de la misma universidad. En la actualidad es investigador adscrito del Instituto Catalán de Patrimonio Cultural ICRPC y se desempeña como docente investigador de la Corporación Unificada Nacional de Educación Superior. Orcid: ID 0000- 0003-2181-3476 
Palabras clave: Monumento histórico, espacio urbano, patrimonio cultural, capital social, historia social

\begin{abstract}
The following research article opens the discussion on monuments by emphasizing a history of the concept. The look on its origin in the Christian West, its relationship with the configuration of the modern Nation State and the understanding of its status as a cultural product, allowed to make the transition to the discussion about the legitimacy of the historical heritage. In the theoretical framework, historical heritage was understood as social and spatial elaboration and as a cultural product caused by social struggles. The objectification of Bogota's historical heritage, in particular of the monuments, required a social history approach as a socio-analysis in order to demonstrate the conditions of its production. This objectification revealed the problem of forgetting the Bogota monuments with the specification of the legitimation circuits in the Bogota social and urban space between 1880 and 1930.
\end{abstract}

Keywords: Historical monument, urban space, cultural heritage, social capital, social history

\title{
Introducción
}

En el mes de septiembre del año 2011 empezó a circular por la ciudad de Bogotá un rumor que causó polémica. Se trataba de la construcción del Conjunto Residencial Quintas del Libertador, un exclusivo conjunto cerrado adscrito a la denominada renovación del centro histórico de la ciudad. Este complejo residencial estaría conformado por 160 apartamentos, distribuidos en tres torres de veinte pisos cada una. La difusión de este proyecto liderado por la constructora INARTCONST S.A, se llevó a cabo por medio de la repartición de brochures por la tradicional Carrera Séptima. 
Tal vez lo más llamativo del folleto era el slogan de la propuesta inmobiliaria donde se hacía una referencia implícita a un lugar mítico: "el hogar que un héroe merece". Este sugestivo juego de palabras indicaba que el espacio propuesto para esta construcción era la Quinta de Bolívar. La conjetura se verificaba cuando aparecía una invitación a despedirse del monumento. De esta manera, se instaba a los ciudadanos a recorrer la casa Museo Quinta de Bolívar por última vez antes de su demolición para dar paso a una de las más importantes obras de la arquitectura moderna en pleno centro histórico de la ciudad ${ }^{3}$.

Los reclamos que se realizaron frente a la amenaza que representaba la construcción de este conjunto residencial llegaron hasta el Ministerio de Cultura, que valga decir, tuvo que aclarar el incidente. Se trataba de una propuesta artística de Jhon Aguasaco, artista visual residente en Barcelona, que ideó este simulacro para fomentar las visitas a la Casa Museo Quinta de Bolívar dentro del marco de la celebración del Patrimonio Nacional en el mes de septiembre ${ }^{4}$. Las preguntas que se desprendieron de este simulacro y por supuesto, las sensaciones por la aparente pérdida de un lugar importante para el centro histórico de la ciudad desatadas por esta falsa noticia generaron diferentes reflexiones. Las preguntas sobre el quién, el para quién y el cómo del patrimonio dejan entrever problemáticas asociadas con la innovación urbana, con las operaciones inmobiliarias y con la defensa del patrimonio en los centros históricos. Para el caso concreto de Bogotá también deja los siguientes interrogantes ¿De quién y para quién es el patrimonio histórico

\footnotetext{
${ }^{3}$ El asombro no se hizo esperar ante una noticia que causó polémicas de todo orden. En el mes de octubre, uno de los sitios más emblemáticos de la historia del país desaparecería para dar paso a unos modernos apartamentos con áreas de $170 \mathrm{~m} 2$ hasta $246 \mathrm{~m} 2$ tal como se presentaba en el folleto de difusión del conjunto residencial. La desazón y la amargura por la pérdida de la historia representada en este lugar, generó toda una serie de sentimientos encontrados que discurrían entre la indignación y la expectativa por contemplar una nueva perspectiva de ciudad. Esta imagen futurista de un mejor porvenir para el centro de la ciudad, no sólo daba la impresión de alejar el mote de "guarida de ladrones" que otrora detentaba este espacio cultural, sino que recrudecía las posiciones más conservadoras en torno a la supervivencia de bienes inmuebles de importancia histórica.

${ }^{4}$ Tranquilos los ánimos para un sector proclive al cuidado de lo patrimonial, se hizo evidente que esta propuesta hacia parte de las iniciativas que pretendían convertir al Museo en un espacio alternativo de proyectos artísticos. Con toda una estrategia de difusión de venta inmobiliaria Aguasaco logró generar una polémica en diferentes medios de comunicación como el diario el tiempo, la revista semana y principalmente entre los bogotanos que quedamos a la espera del desarrollo de esta noticia.
} 
bogotano? ${ }^{5}$, ¿Qué ha pasado con los monumentos de Bogotá? ¿Por qué han caído paulatinamente en el olvido?

\section{Discusión: Valoraciones patrimoniales y la producción de la memoria}

Para lograr responder a los interrogantes antes mencionados, se hizo necesario remontarse a una antigua discusión sobre los orígenes del concepto de monumento para desentrañar sus sentidos y sus usos. Una primera mirada vincula, su origen en el contexto de la revolución francesa y el pensamiento ilustrado que trajo consigo la legitimación de los monumentos y su conservación pública. Una segunda mirada amparada en los planteamientos de la historiadora Francoise Choay desborda las explicaciones de la aparición de los monumentos desde el pensamiento ilustrado y las complejidades de la modernidad. De acuerdo con Lourés Seone (2001) la relación entre el monumento histórico y el patrimonio cultural se remonta al occidente cristiano. Esta época remarca el regreso del Papá Martin a Roma y junto con los humanistas del siglo XV se vuelve la mirada a la antigüedad clásica. Desde 1420 los papás se empeñaron en edificar ciudades grandiosas al estilo de la ciudad antigua y en este sentido, prosperaron normas y decretos para la protección de los monumentos.

En lo que si concuerdan ambas miradas es que la discusión sobre la conservación pública de los monumentos se agudiza con la revolución industrial bajo el establecimiento de fábricas en los campos y la perdida de antiguos contornos de las ciudades. En este escenario aparece la discusión sobre si el desarrollo de las urbes requería una lógica de conservación/destrucción o si por el contrario se instauraba una lógica de conservación/restauración. Bajo la crítica a las ciudades mecanizadas por parte de los socialistas utópicos y la defensa de los monumentos de la ciudad con la aparición de la figura del inspector de monumentos junto con la comisión de monumentos históricos, prosperó entre 1810 y 1840 la teoría de la restauración

\footnotetext{
${ }^{5}$ Esta pregunta está referida a los usos legítimos del patrimonio. El patrimonio como construcción colectiva y como escenario de luchas supone la participación de diferentes agentes en las disposiciones estéticas, éticas y políticas, incluso de propuestas no oficiales del patrimonio y la reivindicación de posturas proscritas del patrimonio como el grafiti.
} 
(Lourés Seone 2001).

A pesar de las diferencias sobre el origen de un discurso asociado a los monumentos, la idea que más ha prosperado es sin duda, la de su vinculación con la producción del Estado y la Nación. La construcción de identidades nacionales y los procesos de cohesión social vieron en la utilización del patrimonio, en especial de los monumentos, una estrategia fundamental para la creación de unas identidades consecuentes con la organización del Estado Nación moderno. Algunos estudios sobre el surgimiento de la Nación y la configuración de la entidad política administrativa denominada Estado, plantearon una relación próxima de los monumentos con la consolidación de unos valores colectivos con el fin de consolidar una comunidad imaginada, también insisten, que bajo una eficacia política del Estado, los monumentos fueron eficientes como dispositivos socializadores que como la educación pública pretendieron unificar y homogeneizar una experiencia de Nación (Anderson 1983; Hobsbawm; 1997) ${ }^{6}$.

Esta visión resultó, además de eficiente, reafirmada en el escenario académico bajo la promoción de unas representaciones del pasado siempre homogéneas y excluyentes. Como sostienen autores como Van der Hammen, Thierre Lulle y Dolly Palacio, la política del patrimonio resultó eficiente para la consolidación del Estado Nación moderno con acciones como la recuperación restauración y conservación del patrimonio. Sin embargo, estas acciones en torno al patrimonio que lo han "definido a partir de una supuesta "objetividad científica", se traduce en clasificaciones que, además de autoritarias, pretenden instituir realidades patrimoniales al amparo de enunciados excluyentes" (Van der Hammen, Thierre Lulle y Dolly Palacio, 2009 p.65).

\footnotetext{
${ }^{6}$ Bajo estas posturas los signos nacionales, entre los que se destacan los monumentos, suelen ser abordados como el reflejo de la sociedad. De esta manera, apelar a una representación histórica de la nación y consolidar unas representaciones materiales en la ciudad, como monumentos, medallones y placas conmemorativas, se convierte en apuesta estatal cuyo fin conduce a la progresiva inserción de los Estados nacientes a los circuitos de la modernización y a la configuración de una identidad nacional abarcadora capaz de albergar diferentes tipos de identidades de tipo étnico, cultural y social.
} 
Así, este tipo de identidades homogéneas lograron invisibilizar las diferencias por medio de recursos eficientes como la pedagogía de los museos y la consolidación de una historia oficial. Por ejemplo, para el caso de América Latina esta tarea la difundió el populismo entre las décadas del treinta al cincuenta. De acuerdo con López de la Roche (2000), el populismo peronista, el populismo vanguardista brasileño y el caso mexicano utilizaron una pedagogía de los museos para consolidar una identidad homogénea amarrada al sentido de lo nacional. Sin embargo, para el caso colombiano lo que se presentó fue un déficit de representaciones integradoras de lo nacional. Desde estas posturas ligadas a las visiones conservadoras del patrimonio en su relación con los relatos fundacionales, los proyectos políticos, y la constitución de los Estados Nacionales, se reivindica una visión homogénea de la conservación de la cultura y de la producción de un pasado común a partir de la consolidación de una historia oficial y de unos dispositivos eficientes para la simbolización de estas representaciones del pasado.

No hay que olvidar que en los procesos de patrimonialización el Estado logra mediante políticas públicas, objetivar el patrimonio en la ciudad, al tener en cuenta que su función reside en el rescate del sentido social del patrimonio como mediador por excelencia de las políticas públicas (Canclini, 1994; Llano, 1994). Una de las principales maneras para regular las formas de sociabilidad en la ciudad, sobreviene por medio del manejo del espacio. Este se presenta a través de la regulación de los usos que acaecen en los lugares públicos de la ciudad; estrategia predilecta del ámbito estatal que busca, predominantemente, una coherencia entre las prácticas de los sujetos en los sitios públicos, con el proyecto oficial que reafirma las posiciones sociales que se imponen en las dinámicas del poder (Llano, 1994, p.231237). El patrimonio histórico, se convierte entonces, en la materialización de dichos modos de vida, por medio de una señal física (Pérgolis, 1994)

Además, el Estado pone a circular unos ritos para insertar unas prácticas y unos valores acordes con unos grupos sociales específicos, que por medio de la ritualización cultural logran incorporar en la cultura unos usos sociales del 
patrimonio $^{7}$. Así, el Patrimonio histórico suele convertirse en el producto de selección y transposición de hechos y rasgos elegidos según los proyectos de legitimación política, que mediante las políticas públicas y la utilización del rito buscan simbolizar las formas públicas del pasado para imponer unos sentidos y valoraciones particulares.

Ahora bien, en esta discusión resulta un poco complejo comprender que detrás de los monumentos, existen diferentes posiciones que luchan por imponer un sentido de lo patrimonial como sentido legítimo de la existencia pública (Serna, 2001; Chavarro \& Llano, 2010). Esta visión del patrimonio que no desconoce las relaciones de fuerza en la construcción social de la realidad, se aleja de las consideraciones que vinculan los monumentos como una representación fiel de una sociedad conducente a un modelo ciudadano. Además, desde esta perspectiva que vincula al patrimonio como un producto cultural sometido a confrontaciones por la imposición de una visión de mundo, se propende por la inclusión de nuevas identidades emergentes y excluidas.

De esta manera se asume que la legitimación de ciertos objetos materiales y simbólicos, de lugares y de prácticas susceptibles de ser patrimonializados, requiere para cada contexto histórico especifico, de una codificación, interpretación e institucionalización, que conllevan en sí mismas una referencia al poder (...) todo patrimonio se constituye a través de una puesta en escena que incluye operaciones de selección, combinación, monumentalización, miniaturalización y olvido, y lo hace al servicio de un proyecto político, en el que se ordena y se da un sentido y una propiedad a ciertos bienes, para establecerlos como "verdaderos"(Bustos, 2010).

Finalmente, lo que deja claro esta discusión es que en la medida en que se insiste en esas versiones de lo patrimonial ancladas a los discursos nacionalistas, que por lo general replican proyectos políticos particulares e incluso estilos de vida

\footnotetext{
${ }^{7}$ La perspectiva sobre el rito depende de la posición de quien lo realiza, así para Canclini retomando a Bourdieu, el rito contribuye a la diferenciación social, mientras que para autores como Calvo (1998), es un momento de la lucha simbólica donde se cuestionan las identidades dominantes, debido a que el rito es operado, en esta ocasión por las posiciones dominadas.
} 
dominantes, la objetivación de las producciones que se denominan monumentos tenderán a reproducir las diferencias sociales.

\section{Aspectos teóricos: El patrimonio histórico como elaboración social y espacial}

Desde la discusión que entromete la legitimación de los monumentos, aparece la necesidad de recurrir a una noción de territorio que ayude a comprender estas relaciones de fuerza en la producción monumental. Las advertencias mencionadas en la discusión de este articulo indican que en términos teóricos se requiere llevar la discusión del territorio más allá de ocupar un espacio, o simplemente tener disposición a alojarse en algún lugar. ${ }^{8}$ Desde un paradigma construccionista, la producción del espacio y de los territorios no solo está asociada a la creación de significados compartidos y de tipificaciones sociales agenciadas desde el lenguaje, sino de legitimaciones y confrontaciones simbólicas por la imposición de unos sentidos legítimos de la existencia en los espacios a modo de ganancias de localización (Gergen \& Gergen, 2011; Berger \& Luckman, 2011; Bourdieu, 1999) ${ }^{9}$.

Para Bourdieu (1999) existe una homología entre las relaciones espaciales y las objetivaciones del espacio social. La confrontación entre los agentes por obtener ganancias de localización se presenta por la obtención de los bienes más escasos como por ejemplo espacios libres de obstrucciones visuales que se convierten en privilegios para ciertos agentes sociales que invierten para su posicionamiento en una lógica de la valoración/ devaluación espacial y social. Precisamente lo que permite la distinción de unos agentes frente a otros es la consecución y posesión de los bienes más escasos en el espacio físico. En este sentido, la confrontación por estos bienes vendría a ser una apuesta por parte de unas posiciones sociales

\footnotetext{
${ }^{8}$ De acuerdo con Lefebvre (1975) estas significaciones del urbanismo clásico han prosperado bajo la noción de hábitat que designa una función y un objetivo del ser humano a ocupar un lugar. Este reduccionismo del hábitat a solo alojarse y detentar un espacio, excluye las relaciones antropológicas y sociológicas en la medida en que el habitar es un hecho antropológico. La habitación, la mansión, el hecho de fijarse al suelo (o de desprenderse de él) el hecho de arraigarse (o de desarraigarse) el hecho de vivir aquí o allá (y por consiguiente el hecho de partir, de ir a otra parte) estos hechos y este conjunto de hechos son inherentes al ser humano (Lefebvre, 1975, p154). Como objeto de reflexión, el hábitat se ha ocupado del valor existencial de la vida humana (Waisman 1985, p36). 9 Las referencias aparecen en el orden de la enunciación las propuestas teóricas planteadas por los autores para no hacer la lectura pesada y desordenada.
} 
con el fin de obtener ganancias de localización, donde los bienes más encarecidos se ubicarían en una posición favorable frente a otros lugares menos valorizados ${ }^{10}$.

En este sentido Indagar por las condiciones de elaboración del Patrimonio Histórico requiere tener presente los diferentes conflictos que se pueden generar en torno a la producción de diferentes formas de representación y conservación de la memoria en el espacio (Serna, 2001; Serna, 2010; Chavarro \& Llano, 2010). Como inversión simbólica, el patrimonio requiere de un agenciamiento de diferentes instancias y posiciones sociales, que por lo general están en una posición dominante para lograr su objetivación y reforzar de esta manera los espacios ritualizados de la ciudad. Estos discursos que circulan en la ciudad, movilizan diferentes intencionalidades alrededor de la legitimación de lo patrimonial. Aquí también intervienen las representaciones que ponen a circular arquitectos, historiadores, antropólogos, filósofos y sociólogos para posicionar un punto de vista alrededor de los objetos patrimoniales y su institucionalización.

Para que el patrimonio histórico en su condición de mecanismo simbólico, pueda operar como producto cultural, se hace necesario principalmente la inversión que pueda procurarle el campo de la arquitectura, sumado a la fuerza simbólica del campo de la producción de la historia. Desde la arquitectura se afirma el valor que representa para un lugar el patrimonio histórico. En el espacio construido y en la intervención arquitectónica, las diferentes valoraciones que se desprenden del patrimonio tienen la capacidad de generar cohesión dentro de los grupos sociales (Pérgolis, 1994, Viviescas: 1994, Moure: 1994; Lombardi, 1994; Saldarriaga, 2002).

\footnotetext{
${ }^{10}$ De este modo se hace evidente una lucha constante entre diferentes posiciones por la clasificación social, que además de ser producto de la historia, proceden bajo las estructuraciones económicas sociales y culturales, que, sometidas a la fuerza de la historia, incorporan las desigualdades como fenómenos naturales. Los efectos de lugar se hacen evidentes en las bajo acatamientos silenciosos de las valoraciones y devaluaciones sociales y espaciales. Estas dinámicas del espacio físico y social quedan claramente expuestas por el autor al estudiar el fenómeno del guetto. Como afirma Wacquant (2006), las apreciaciones que desconocen las configuraciones históricas ocultan las diferencias sociales y económicas en las dinámicas urbanas, amparadas en políticas de invisibilización de la pobreza, políticas que posibilitan la estigmatización de espacios que tienden a la involución económica y al deterioro social.
} 
Desde la historia, la producción y proyección de unas imágenes, conceptos y discursos en el espacio social y urbano, permite a los productores de la historia imponer mediante las valoraciones dadas a los monumentos una representación legítima de la historia ${ }^{11}$.

Finalmente, esta discusión entromete necesariamente la existencia de unos campos relativamente autónomos dedicados a la construcción del discurso sobre lo espacial y sobre las representaciones del pasado que tienden a circular por la ciudad en la forma de dispositivos, manuales escolares y obras de arquitectura entre otros. En efecto, estas luchas tienen su concreción en la ciudad con los agenciamientos de diferentes grupos en el espacio social para objetivar unos valores sociales en el espacio físico. De esta manera, el patrimonio se convierte una de las estrategias utilizadas por las elites para desactivar las contradicciones sociales y naturalizar las posiciones en el espacio social a través de legitimación de estilos de vida dominantes (Chavarro \& Llano, 2010). Las representaciones del pasado cobran valor indiscutible para las sociedades de tipo Estatal, que lo interpone para la promoción de una identidad nacional bajo los efectos de la historia oficial que requiere ser difundida por un campo educativo que pone en circulación discursos conceptos e imágenes sobre un pasado que se muestra inherente a la sociedad.

\section{Metodología.}

La indagación que se realizó sobre los monumentos bogotanos se hizo desde la historia social como socioanálisis. Desde esta práctica reflexiva de investigación se abordó el estudio del patrimonio histórico en el espacio social y urbano bogotano. Este patrimonio conceptualizado como producto cultural proveniente de las luchas por la imposición de un sentido legítimo de lo histórico y lo público requirió desde el análisis de las relaciones de poder, objetivar las condiciones de producción de los monumentos. Con una vigilancia sobre el objeto de estudio, en este caso el

\footnotetext{
${ }^{11}$ las versiones del pasado, son agenciadas por unas posiciones pertenecientes al campo de la producción de la historia, posiciones que buscan obtener el monopolio de unas formas públicas de la misma, con el fin de obtener e imponer la forma legítima de contar la historia y de ese modo aplicar un principio de visión y de división del campo de la producción de la historia.
} 
patrimonio histórico, la estrategia del socioanálisis como historia social permitió acceder a las condiciones de posibilidad del patrimonio como producto cultural provocado por las relaciones de fuerza, al hacer evidente el problema real del patrimonio centrado en su desigual apropiación y en las luchas por la imposición de un principio de visión y de división del mundo social. De esta manera al involucrar una dimensión social e histórica sobre el espacio urbano, se dio importancia a un pensamiento relacional para comprender redes, nodos y abrir la posibilidad de análisis de sistemas complejos ${ }^{12}$.

Desde un enfoque de historia social se optó por la reconstrucción de las condiciones de su producción de los monumentos bogotanos tras el rastreo de estructuraciones en el plano económico, urbano y social bajo la categoría de espacio social. El abordaje metodológico requirió de un complemento conceptual potente para rehistorizar las condiciones de producción de los monumentos con la profundidad que ofrecen algunos insumos teóricos, como las nociones de campo, capital y habitus provenientes de la sociología de Pierre Bourdieu.

Como estrategia metodológica se asumio el analisis de fuentes documentales de primera mano como la prensa de la época como Diario el Espectador (1891-1930) diario el Tiempo (1910-1935), Papel periódico lustrado 1881-1888) y revistas, tales como Cromos (1916-1938), El Gráfico (1910-1935), Mundo al Día (1924-1930) tambien este análisis documental operó con el rastreo de fuentes secundarias en relación a la ciudad de Bogotá en cuanto a la vida urbana, la transformación del mobiliario urbano, los principales cambios económicos para realizar el levantamiento de los monumentos bogotanos. Este levantamiento de un inventario

\footnotetext{
${ }^{12}$ Esta posibilidad de complementar conceptos provenientes de la sociología con formas de hacer historia puede llevar a complemento de enfoques. Según Peter Burke, el enfoque histórico y el de la teoría social, aunque se han juzgado contradictorios, pueden ser complementarios en la medida en que los cambios en el método y los giros históricos han propuesto nuevos enfoques como la sociología histórica, historia social, historia cultural (Burke, 2007). Desde esta línea argumentativa, el concepto de campo (literario, lingüístico, artístico, intelectual) de Bourdieu se refiere a un ámbito autónomo, que adquiere independencia en un momento concreto en una determinada cultura y genera sus propias convenciones culturales. La idea de un campo cultural no ha atraído hasta la fecha a demasiados historiadores, aunque el concepto en cuestión se les ha antojado iluminador a los estudiosos de la literatura francesa y del surgimiento de lo intelectual (Burke, 2012 p.77).
} 
de los monumentos, estatuas y bustos que aparecieron en la ciudad entre 1880 y 1938 se complementó con las estructuraciones económicas y sociales del espacio social y urbano bogotano para profundizar en los sentidos que adquirieron las grandes celebraciones ${ }^{13}$.

Por último, para esta investigación las crónicas de viaje constituyeron una fuente muy apreciada para la descripción de la vida cotidiana. Sin embargo, se consideró que no constituye un testimonio de primera mano, en la medida en que se exponen desde el punto de vista de un espectador no involucrado con el contexto, que, además, solo disponía de un periodo limitado de tiempo para sus observaciones.

\section{Resultados:}

\section{El patrimonio como inversión privada: De los patrimonios familiares a la simbolización de lo íntimo (1880-1910)}

El espacio social y urbano bogotano de finales del siglo XIX y las primeras décadas del XX albergó una serie de contradicciones que ralentizaron su consolidación como ciudad moderna. Una de las primeras ambigüedades de este proceso fue sin duda la lenta transformación de un espacio urbano precario de corte colonial a un paisaje urbano. Este tránsito se hizo evidente en la lenta desaparición de las plazas de mercado coloniales a la configuración de un paisaje urbano que incluía plazas conmemorativas a los héroes de la patria. Sin que fuera evidente su crecimiento y densificación, el espacio social y urbano bogotano permaneció en sus límites reducidos entre la calle 26 hasta la calle 1 y desde la actual carrera 2 hasta la carrera 14. Las pocas inversiones en el espacio urbano estaban vinculadas a introducir prácticas culturales extranjeras como el teatro que buscaban la diferenciación social

\footnotetext{
13 De esta manera, este inventario buscó resolver los siguientes interrogantes En primer lugar ¿Quienes proponían el patrimonio para el espacios social y urbano bogotano? Con esta pregunta se buscó conocer a los agentes del espacio social que participaron de la producción del patrimonio. En segundo lugar ¿Cómo se diseñaron? a partir de esta pregunta se conoció los materiales de su construcción, sus dimensiones, así como otras propiedades estéticas del patrimonio. En tercer lugar ¿Cómo se emplazaron? ¿En efecto, se indagó por los lugares de emplazamiento puesto que la ubicación en determinado lugar del monumento le aumenta su valor social? En cuarto lugar ¿Por qué estos emplazamientos o incluso destrucción se convirtieron en objeto de luchas?
} 
de las clases sociales dominantes frente a las populares.

En un espacio urbano estrecho y poco dinámico, donde valga decir eran escasos los lugares de sociabilidad pública, la vida urbana era más bien escasa. Lugares de encuentro como el altozano de la catedral, las chicherias que se resistian a desaparecer de la estructura urbana y uno que otro Café, reducian las posibilidades de intercambio cultural y participación social en el espacio público. Con algunas excepciones como la reforma de la plaza mayor y el inicio en la construcción del capitolio Nacional a finales de la primera mitad del siglo XIX, la arquitectura bogotana era predominantemente de tipo religioso. Con calles estrechas, casas de un solo piso y escasos escenarios públicos como plazas, parques y sitios de diversión, el espacio urbano bogotano carente de una vida pública animada por eventos civiles y seculares, se resguardó en el dominio de la vida intima y en los espacios privados (Llano,2019).

En este panarama, la distinción social se reforzaba en la apariencia y en una práctica cultural anquilosada en el universo colonial que consistia en las reuniones al interior de las casas. Al escasear los lugares públicos donde se podía realizar la diferenciación de los grupos sociales bogotanos, los habitantes de la elite, reforzaron estas diferencias sociales muchas veces en los lugares privados, debido a la cercanía espacial con las demás clases sociales (Serna, 2001, Chavarro \& Llano 2010). En este sentido, se buscó la distinción social, no tanto en las adecuaciones arquitectónicas y en el embellecimiento de las casas, sino más bien en resaltar las diferencias en las apariencias y en algunos atributos distintivos como el hablar y vestirse bien dentro de los parámetros civilizatorios. De esta manera, la élite, instrumentalizó la cultura para dirigir el rumbo de la sociedad en los procesos civilizatorios para dejar atrás lo que entendían por barbarie: hablar y vestirse mal y tener un comportamiento ajeno a las reglas dictadas por los manuales de urbanidad (Zambrano, 2002, p119)

Así, el universo social bogotano estructurado en el siglo XIX, presenció cambios intermitentes concernientes a las nuevas configuraciones de los estilos de vida inscritos en el paradigma civilizatorio. Estas nuevas preocupaciones por lo moderno, 
por lo culturalmente legítimo, generaron nuevas motivaciones de tipo económico, social y cultural, frente al viejo molde colonial de estructuraciones sociales. Esta ambivalencia en las dinámicas sociales y culturales se proyectaron en primer lugar en el campo económico, donde una de las principales transformaciones estaba encarnada en los cambios en la estructura colonial gracias a los flujos económicos provenientes de una economía que empezaba a consolidar el café como producto nacional ${ }^{14}$.

Con pocas inversiones en el espacio urbano, la simbolización del pasado en el espacio público se redujo a escasas celebraciones de tipo patriótico en las plazas públicas y a la rememoración y exaltación de personajes en el cementerio central ${ }^{15}$. En este escenario, el patrimonio histórico como un producto cultural tuvo unas particularidades. En relación a la conservación de la memoria se buscó referenciar a personajes de la vida pública y a la conmemoración de sus acciones para lograr articular los mitos fundacionales y enaltecer los héroes de la patria. Tras desterrar la práctica de entierros en las iglesias y evitar las fuertes epidemias que afectaron la ciudad por la inhumación de los cadáveres, el Cementerio Central se convirtió en un escenario proclive para simbolizar la memoria de aquellos personajes que entraron a ser parte del panteón patriótico.

Como inversión privada, la práctica de levantar monumentos en el Cementerio Central, la ejercían aquellas personas prestantes quienes buscaban desde la opulencia, la glorificación de los muertos. Entre los monumentos más representativos emplazados en las últimas décadas del siglo XIX en el Cementerio

\footnotetext{
${ }^{14}$ Aunque una parte de la elite venia invirtiendo en las pequeñas industrias familiares, el clima económico no les fue muy favorable. Solo hasta que empezó a despegar la industria cafetera, estas inversiones en las industrias de la ciudad se hicieron mucho más visibles. A partir de 1880 se evidencia una decadencia de las exportaciones en el país producto del abandono de la política del libre cambio bajo la orientación de Rafael Núñez. Aunque, la tendencia global parece haber sido el estancamiento de las exportaciones, detrás de esto se ocultaba el comportamiento muy dinámico del café, que pasó a representar casi el 50\% del total de las exportaciones (Melo, 1989 p 82).

${ }^{15}$ Declarado en 1984 monumento nacional, el cementerio central se convirtió desde finales del siglo XIX hasta los años cincuenta del siglo XX en el escenario propicio para exaltar la memoria de políticos, militares y figuras literarias y también en el escenario de luchas por el control del pasado. La necrópolis fue el escenario predilecto para la disputa de la hegemonía de la historia colombiana (Vignolo p, 2013)
} 
Central, se encontraron los erigidos a José Eusebio Caro, donado por sus nietos, el de Juan José Neira, José Eusebio Otálora, Lázaro María Pérez y el de Ezequiel Rojas, fundador del partido liberal. Este último fue adelantado por su viuda quien delegó la tarea a P Costa Florentino, escultor reconocido, que elaboró en mármol blanco el busto del prestante personaje.

No parecía claro quién debía agenciar esta empresa destinada a imponer las formas legítimas de la historia en el país, ya que los agentes privados, se hacían cargo del direccionamiento de los monumentos como inversiones privadas, como por ejemplo la donación que realizo José Ignacio París al congreso de la república importando desde Italia una escultura relativa al máximo héroe de la patria. Diseñada por el escultor italiano Pietro Teneranni, fundador de la iconografía bolivariana, esta escultura tenía como fin adornar la casa quinta, posteriormente conocida como el Museo Quinta de Bolívar, cuyo dueño era el mismo Paris en $1846^{16}$.

De otro lado, con la muerte del Presidente Rafael Núñez en 1894, se hizo cargo de la presidencia Miguel Antonio Caro, un reconocido gramático, que enfrentó a la oposición liberal y algunos sectores de la burguesía financiera con fuertes medidas económicas que giraron alrededor del cambio del patrón oro por el papel moneda de curso forzoso. Esta pérdida del predominio económico basado en el monopolio del crédito y el libre ejercicio de la usura exacerbó los ánimos de la oposición, al punto que el liberalismo creyó dada las condiciones objetivas para lanzarse a una fácil y nueva aventura militar que lo condujera a la toma del poder (Jaramillo, 1989, p66).

Esta contienda que se inició el 22 de enero de 1895 conocida como la contienda de los sesenta días es el antecedente más inmediato de una de las guerras más

\footnotetext{
${ }^{16}$ En un acto de filantropía este personaje desprendido, sin razón aparente dona al Congreso el 12 de mayo de 1846 la estatua ecuestre de simón Bolívar y la de José María Castillo y Rada, emplazada en la capilla del colegio el Rosario. Tal como afirma Cortázar "inicialmente la escultura de Bolívar tenía como destino el lugar de residencia de Ignacio Paris, pero, este finalmente terminó por donarla al Congreso de la República, quien dispuso se colocará en la plaza principal de Bogotá, delante del Capitolio (Cortázar, 1938).
} 
crueles y sentidas en el territorio colombiano conocida como la guerra de los mil días. En este ambiente de disputas, la postergación de lo simbólico predominó y de esta manera se redujeron los escenarios para la proyección pública. Ahora bien, la consecuencia directa de esta acción era la incapacidad para imponer en el espacio urbano, unos contenidos legítimos a través de los emplazamientos, ya que al ser apuestas privadas no conseguían ninguna publicitación de la historia ${ }^{17}$.

Sumado a esta falta de políticas públicas y a la ausencia de instancias destinadas para la protección y divulgación de la memoria nacional, la postergación y la poca producción de monumentos fue una práctica constante durante todo el siglo XIX. EI caso más sobresaliente lo constituyó la erección de las estatuas de la reina Isabel y Cristóbal Colón dentro de la celebración del IV centenario del descubrimiento de América en 1892, pues bien, estos monumentos fueron emplazados diez y seis años después de haber salido la ley 58 de 1890 que las autorizaba, en parte por la precariedad del presupuesto municipal, "de los monumentos aprobados oficialmente para Bogotá hasta 1891 estaba pendiente la construcción de 18" (Tovar, 1997, p. 147)

En 1892 solamente se relacionaban los siguientes monumentos: estatuas de Bolívar, estatua de Santander estatua de Mosquera, monumento al centenario mausoleo de Neira, busto de Acevedo y Gómez mausoleo de Castillo y Rada, lapida a Francisco José de Caldas, lápida conmemorativa de la salvación del Libertador, mausoleo de Jiménez de Quesada, y el monumento a los Mártires que llevaba la inscripción delce et decorum est pro patria mori (Tovar. 1997). Este último representaba una alegoría que resaltaba la encarnación de los soldados acribillados en la huerta de Jaime, posteriormente bautizada plaza de los mártires.

\footnotetext{
${ }^{17}$ Esto es significativo, si se tiene en cuenta que, apelar a los personajes de la historia, puede ser un recurso retórico donde se aplica todo el peso del pasado en una representación del presente, convirtiendo a los seres mortales, en seres míticos donde se hace abstracción de aspectos negativos y donde la identificación simbólica con las imágenes de los patriotas constituye la identidad de los ciudadanos (Tovar: 1997; Sánchez: 2003). No obstante, este tipo de representaciones de finales del siglo XIX por pertenecer al tiempo presente y al no tener el agenciamiento público, no lograban acudir a este tipo de recurso.
} 
Finalmente, otra parte de este inventario de monumentos de finales del siglo XIX, pertenecía al orden de lo simbólico, como en el caso del monumento levantado a Luis A. Robles considerado el primer monumento moderno en el país. Con una ausencia de representación estatal y unos intereses ligados a la conservación de la memoria de familiares, se arraigó una práctica privada de producción monumental durante el siglo XIX. Estas discusiones en torno a la definición de lo patrimonial, para la época no reflejo la pertinencia de la producción de monumentos y el posicionamiento de elementos simbólicos relacionados con la configuración de lo nacional.

\section{La Academia Colombiana de Historia: Las condiciones que hicieron posible el campo de la historia}

La crisis política que desató la guerra de los mil días y la separación de Panamá sumado a las diferentes guerras civiles que dejó el siglo XIX proclamó una alerta en el país de falta de patriotismo y ausencia educativa en la enseñanza de la historia. Desde comienzos del siglo XX, el caldo de cultivo para la creación de una academia de Historia tomaba forma. El gobierno del vicepresidente José Manuel Marroquín, por mediación del Ministro de Instrucción Pública, José Joaquín Casas, expidió el 9 de mayo de 1902 la resolución 115, por medio de la cual se estableció una Comisión de Historia y Antigüedades Patrias.

Considerando: Que por la incuria y por la triste situación del país, día por día se van perdiendo irreparablemente multitud de documentos preciosos, de monumentos y datos de todo género, que constituyen material histórico de grande importancia para Colombia (Velandía, 1988: p.26)

Una vez constituida como academia, el gobierno la dotó de autonomía para la recuperación y preservación de documentos y objetos valiosos, así como la de ejercer como veedor de las obras especializadas de historia nacional ${ }^{18}$. Ahora bien,

18 De acuerdo con Velandía, (1988) la institución se inició con 19 miembros. En ella confluían personajes de diferente talla que componían los miembros de número de esta institución, se encontraban por ejemplo, personajes relativos a la milicia como generales, otros eran agentes de la 
es importante mencionar que el campo de la producción de la historia que para entonces se estaba organizando, no contó con historiadores profesionales en la medida en que el capital que estructuraba los campos de la producción cultural operaban alrededor del uso correcto del lenguaje (Llano, 2019). En esta medida narración histórica, pulcritud lingüística y uso correcto del idioma, se entremezclaron en un capital cultural de tanta importancia que tenía una relación directa con el campo del poder. La relación entre gramática y poder se decantó en el uso correcto del lenguaje, en el uso de galicismos y en la defensa contra toda suerte anglicismos que amenazaran la tradicional forma de concebir un proyecto cultural reafirmado sobre la conexión con España (Deas,1993).

No es extraño, que algunos miembros de la Academia Colombiana de la Lengua (ACL) fundada en 1871 por José María Vergara y Vergara, Manuel Marroquín, Miguel Antonio Caro y otros tantos filólogos y gramáticos, hicieran también parte de la Academia Colombiana de Historia $(\mathrm{ACH})$. Esta delegación del monopolio del conocimiento histórico legítimo, en la $\mathrm{ACH}$, permitió propagar el saber histórico desde dispositivos socializadores como la educación pública con manuales específicos de enseñanza de la historia (Serna, 2001).

Finalmente, con un campo de la historia soportado sobre la falta de patriotismo y la necesidad de formar a un ciudadano en valores patrióticos, aparece la necesidad de enaltecer la figura del héroe nacional. En este orden de ideas, el papel de la academia en la instauración de estrategias destinadas a la movilización del sentido histórico resultó más que determinante.

De las evocaciones del centenario a la celebración del cumpleaños de Bogotá

producción literaria, algunos graduados en derecho, y otros sin titulación, como en el caso de Eduardo Posada quien fuera uno de sus fundadores; el manejo de un capital cultural acorde con las disposiciones del gobierno, parece ser un elemento fundamental para la pertenencia a la academia y por supuesto para la adquisición de capital simbólico. La mayoría de estos personajes se encontraba cerca al gobierno, por ejemplo, Cordovez Moure uno de los miembros fundadores de la academia, sirvió al ministerio del tesoro bajo la presidencia de José Manuel Marroquín. Los personajes de la academia no eran historiadores profesionales, sin embargo, todos tenían publicaciones. 


\section{(Bogotá 1910-1938)}

En el gobierno de Rafael Reyes (1904-1909) se estableció la ley 39 del 15 de junio de 1907 que autorizaba la celebración del centenario de la independencia nacional. Esta celebración contempló una comisión encargada de los preparativos junto con la preparación de la edición del libro el centenario de la independencia 1810-1910. La celebración del centenario duró diecisiete días y durante este periodo de tiempo se inaugura gran número de estatuas, bustos, medallones y retratos en toda la ciudad. Esta celebración, intento mostrar una representación de la nación que superará a cuantas se habían efectuado en el país en ocasiones anteriores, lo que sin ninguna duda se logró (Martínez ,2000).

En el primer decenio del siglo XX existe una indecisión entre la representación productiva de la nación o la representación cultural en las exposiciones, en este orden de ideas, se enfrentan dos tendencias. En primera instancia, la Exposición Nacional inaugurada por Rafael Reyes en el bosque del centenario de Bogotá el 20 de julio de 1907 mostraba una orientación marcadamente industrial y la exposición del centenario (1910) producto de la ideología de la hegemonía conservadora reflejaba una visión predominantemente cultural de la nación. Para la segunda de ellas, "Nacionalismo, catolicismo, modernismo industrial, hispanismo, exaltación de la independencia se juntan en la representación de Colombia". De esta manera queda excluida la representación del pasado indígena con un predominio de las fiestas patrias y el discurso hispanista convirtiéndose en toda una empresa de catequización nacionalista y católica en torno a unos ídolos de bronce y al poder cohesivo de la iglesia (Martínez, 2000, p.330) ${ }^{19}$.

A comienzos del siglo XX una gran producción de monumentos se relacionó con las

\footnotetext{
${ }^{19}$ Lo anterior muestra que el tipo de representación que orientaba las luchas entre unos agentes de la producción cultural, obedecía a la figura del patriota. Las figuras representadas en los monumentos correspondían a personajes del pasado donde se privilegiaba la rememoración, se trataba entonces de recubrir al personaje con la figura retórica del mito que engrandece las capacidades del personaje convirtiendo los seres mortales en personajes míticos, así pues, los hijos glorificando a sus padres se glorifican a sí mismos (Tovar, 1997).
} 
conmemoraciones del centenario de la independencia en 1910 y la liberación completa de España en 1919. Las mayores adecuaciones se hicieron en torno a plazas y parques. La más sobresaliente fue la del parque de la independencia, que albergó la exposición nacional con la erección de diversos monumentos; entre ellos se encontraban, el de Julio Arboleda, Murillo Toro, Salvador Camacho Roldán y el monumento a Bolívar; todos estos monumentos fueron acordados por ley.

Ahora bien, en esta producción de monumentos también aparecieron algunas contradicciones. De acuerdo con Ovalle (2013) de los catorce monumentos decretados para la celebración del Centenario solo tres fueron financiados por el Estado $^{20}$. De esta manera se hace evidente que los monumentos que se emplazaron en el espacio social y urbano bogotano se inscribieron dentro del conjunto de estrategias dirigidas a la apertura pública de la ciudad a través de las expectativas de las clases en ascenso. En efecto, aunque el periodo comprendido entre 1910 y 1938 se encuentra caracterizado por las continuas fluctuaciones de la economía a nivel y nacional, en realidad fue un periodo de expansión financiera que permitió a las clases dominantes la oportunidad de imprimirle al espacio urbano

${ }^{20}$ Entre los monumentos donados por instituciones y personas privadas están: Busto de Antonio Ricaurte en el Parque del centenario, donado por el Gun Club, Busto de Acevedo Gómez en el Palacio Municipal donado por la sociedad de la Unión, Busto de Camilo Torres en el Parque del Centenario, donado por el Jockey Club, Medallones de Fernández Madrid y de Vargas Tejada en el Teatro Colón, donados por el escultor Juan José Rosas al Jockey Club y por este al teatro Colón; Monumento al canónigo magistral Andrés rosillo en la Plazuela de la Capuchina, donados por los vecinos del barrio San Victorino a través de la Junta del centenario del Barrio San Victorino, Busto de Antonio Nariño en el salón de sesiones de la municipalidad, donado por la Sociedad Tipográfica, Busto de Francisco José de Caldas en la Facultad de matemáticas e ingeniería, donado por los alumnos de la facultad; Quiosco de la Luz en el parque del Centenario, donado por los hermanos Tomás y José María Samper Brush, Estatua de Policarca Salavarrieta en la plazuela que lleva su nombre, donada por los vecinos del barrio las aguas a través de la Junta del Centenario del Barrio las Aguas, Busto de Francisco José de Caldas en la Plazuela de las Nieves, donado por el Polo Club; monumento a los héroes anónimos en el parque del Centenario, donado por la sociedad de la Caridad. De los monumentos donados por el Estado se encontraban Estatua de Antonio Nariño en la Plaza de Nariño, donada a través de la Comisión Nacional del Centenario, la estatua ecuestre del libertador en el Parque del Centenario, donada por el gobierno a través de la Comisión Nacional del Centenario y por último, la estatua del mariscal Sucre en la plazuela de la Capuchina, donada por el gobierno a través de la Comisión Nacional del Centenario (Ovalle, 2013, p24,25). 
fuertes adecuaciones para la visibilización de sus propios estilos de vida ${ }^{21}$.

El direccionamiento de los monumentos hacia la vida pública es una de las características importantes de este periodo. Algunos de los monumentos fueron iniciativa de sociedades privadas que participaban en el embellecimiento de la ciudad. un ejemplo de lo anterior lo representó la Sociedad de la Caridad encargada de emplazar el monumento a los héroes ignotos. Este monumento elaborado en columna corintia de piedra fue emplazado en el parque de la independencia en el año de 1910. Para esta misma celebración, las sociedades de carácter privado promovieron conmemoraciones a héroes de la patria como en el caso de la estatua de Caldas, promovida por el Polo Club. Este monumento fue emplazado e inaugurado en la Plaza de las Nieves con gran pompa en compañía de la colonia payanesa el 6 de agosto de 1910. Otro ejemplo fue el caso del Jockey Club de Colombia que logro emplazar el busto en bronce de Camilo Torres en la Plaza de la Capuchina. Esta obra fue esculpida por Verlet de París y el arquitecto Clane quien fue encargado del pedestal.

Otras de las sociedades dispuestas para las adecuaciones urbanas fueron: la Sociedad de Embellecimiento y la Sociedad de Mejoras y Ornatos. La primera de ellas apareció entrando el segundo gran momento de emplazamiento de monumentos, ubicado a partir de los años veinte por su correspondencia con el auge económico que vivió la ciudad para la época. Prueba de este esplendor se encuentra en la representación de progreso que hizo la sociedad de embellecimiento al momento de emplazar como monumento, la primera locomotora que recorrió la sabana de Bogotá, en la estación del F.C de Cundinamarca para el año de 1920.

\footnotetext{
${ }^{21}$ Las razones económicas para tales adecuaciones en el espacio urbano provenían de los capitales producto de la indemnización de Panamá y el ingreso a los flujos económicos internacionales del país a través del café. Como consecuencia de esto el Estado se ve mucho más comprometido con las inversiones simbólicas. De este modo, a las inversiones del Estado se suman las proyecciones de una nueva clase ascendente de tipo burgués que utilizó la estrategia del sentido histórico para naturalizar las condiciones del espacio social por medio de las adecuaciones en el espacio urbano. En este sentido el clima nacionalista provocado por la pérdida de Panamá y las celebraciones patrióticas, que las reforzaban, sirvieron como caldo de cultivo para dichas apuestas.
} 
Otra de estas apuestas de las clases en ascenso se encuentra con el monumento elevado en 1923 a Luis Pasteur en la terraza que obtendría su nombre. Este emplazamiento fue adelantado por la sociedad de embellecimiento y es especialmente representativo, puesto que, amplia las imágenes de los monumentos que se concentraban en los próceres para darle paso a la imagen del científico que se constituye como el prohombre modelo de la civilización moderna que la nación debería alcanzar Este segundo momento tiene como puntos más álgidos la celebración del centenario de la muerte de Bolívar (1930) y el cuarto centenario de la fundación de Bogotá (1938). Para el primer caso, el monumento más representativo lo constituyó, el busto en mármol de Bolívar levantado por el Estado en ocasión del centenario de su muerte en 1930. Esta escultura fue modelada por M Benlliure y fundida en Madrid por Ferrero para ser emplazada en el edificio del Banco de la República. Para el segundo caso, la gran cantidad de estatuas, bustos y medallones esparcidos por la ciudad fueron acompañadas por ediciones que conmemoraban el cumpleaños de Bogotá por todo lo alto ${ }^{22}$.

Finalmente, se encuentra que la producción de monumentos para este periodo histórico fue significativa debido a las condiciones económicas que posibilitaron las apuestas de la clase alta dominante. Si se tiene en cuenta que el espacio urbano mostraba algunas transformaciones importantes como la introducción de elementos de arquitectura moderna, se hace evidente la consolidación del hábitat urbano bogotano. Desde estas transformaciones aparecen confrontaciones relevantes en relación con la transformación de la estructura urbana. El caso más significativo fue el de la demolición en 1939 de uno de los signos más representativos de la colonia, se trataba del convento de Santo Domingo demolido por el Ministerio de Obras Públicas para dar paso al Palacio de las Comunicaciones. ${ }^{23}$

\footnotetext{
22 Ver Cortázar R (1938) Monumentos, estatuas, bustos, medallones y placas conmemorativas existentes en Bogotá en 1938 editorial selecta

${ }^{23}$ Para ampliar la polémica sobre la construcción del nombrado palacio de comunicaciones hoy edificio Murillo Toro tras la destrucción del convento de santo domingo ver Rueda L. 2012. y (Muñoz, 2010)
} 
Los argumentos que se utilizaron para suprimir los signos coloniales de la trama urbana se relacionaron con el salto a la ciudad moderna. En estas discusiones aumentó la participación del campo de la arquitectura, que posterior a esta confrontación se encontró con otra disyuntiva en el desarrollo urbano de la ciudad ${ }^{24}$. Por otra parte, para este periodo nacían otras instancias que le hacían contrapeso a la Academia Colombiana de Historia en la delegación de lo patrimoniable. En 1939 se estableció, en el currículo de la escuela normal superior la materia de etnología, la cual contemplaba la formación en arqueología. De otro lado, a partir de 1936 llegan a Colombia profesores pioneros en la arqueología como el caso de Rivet, Bolinder y Shotelius. La profesionalización de estas disciplinas era inminente y esto se ve claramente cuando en 1941 se erigió el Instituto Etnológico Nacional, primer centro de formación en las disciplinas de antropología.

El 9 de abril de 1948 marcó un hito histórico para el país con la desaparición del caudillo Jorge Eliecer Gaitán. Asociadas a las representaciones vandálicas de las clases bajas de la ciudad, se contempló el tema educativo como posibilidad indiscutible de reorganización social de la población. En este sentido, la educación desbordó los límites meramente escolares para proyectarse como un interés de instancias como la $\mathrm{ACH}$ (Academia Colombiana de Historia), quienes se pronunciaron sobre el deber ser de la enseñanza de la historia argumentando que estos hechos lamentables se habían originado por falta de patriotismo y por la ignorancia del pueblo. Esta difusión pública de la historia, tuvo como escenario constante la imagen de la antigua ciudad frente a las proyecciones de la élite por una nueva imagen de la urbe; con una ciudad semidestruida, el desalojo de los barrios sórdidos y la planificación de una nueva imagen de ciudad, se convirtió en la apuesta de unos grupos sociales en torno a la constitución de unas nuevas formas de organización del espacio urbano.

En síntesis, se encuentra que la difusión pública de la historia entra a obtener unas

${ }^{24}$ Se trataba por un lado de acelerar el crecimiento de la ciudad, y de otro solucionar las problemáticas urbanas producto de la migración del campo a causa de la violencia de medio siglo, propulsada por el desastre urbano que implicó el 9 de abril de 1948. 
nuevas configuraciones debido al rápido crecimiento de la ciudad. La apuesta de unos grupos sociales para legitimarse en el espacio social, entra redefinirse, puesto que los sáberes patrióticos ya no encuentran una forma de asirse en los monumentos. El escenario de las luchas se desplaza al orden de lo urbano donde se empiezan a constituir unas nuevas formas de organización del espacio urbano tras los sucesos acaecidos del 9 de abril de 1948, donde la ciudad queda semidestruida.

\section{Conclusiones}

El recorrido que se ha realizado hasta este punto deja abierta una discusión interesante en relación con la producción monumental. Más allá de comprender las grandes celebraciones de tipo histórico desde la rememoración de personajes del pasado resaltando sus hazañas y su sentido patriótico, se hace necesario reflexionar sobre la importancia de reconocer, desde las confrontaciones y las relaciones de fuerza, el carácter de producto cultural que adquiere el patrimonio cultural. En este orden de ideas, es necesario reconocer a las diferentes agencias y agentes que buscan promover representaciones de lo patrimonial.

De esta manera, se hace cada vez más urgente una historia social del patrimonio cultural para comprender los diferentes sentidos y significados de los monumentos y el patrimonio cultural en un país como Colombia. Dadas las desigualdades económicas y sociales que histórica y estructuralmente se han mantenido en el país, la comprensión de unos repertorios simbólicos, que se han estructurado para reproducir en parte las diferencias sociales, permitirá el rescate de unos patrimonios frágiles bajo la exploración de elementos identitarios que representen a diferentes grupos sociales y culturales.

Como objeto de enseñanza, el patrimonio cultural se podrá abordar desde la enseñanza de la historia y desde el desarrollo de un pensamiento crítico y relacional para superar esa formación memorística reafirmada en el aprendizaje de las fechas y los nombres importantes que fundaron la patria. En este sentido, se busca reconocer nuevos signos y símbolos nacionales reafirmados en la cultura y en la 
tarea cada vez más confusa de rastrear la construcción social de lo público.

Finalmente, el presente articulo pretendió mostrar cómo en un espacio social y urbano como el bogotano se estructuró entre finales del siglo XIX y comienzos del $X X$ una ciudad de vecinos, con unos patrimonios familiares. Como estrategias culturales, los monumentos fueron eficientes para simbolizar en el espacio público las expectativas de las clases sociales en ascenso. En este proceso de legitimación. el estudio del patrimonio Histórico se ha debatido entre las visiones más optimistas, que lo entienden como unos objetos que provienen de las más altas aspiraciones espirituales y culturales, hasta posturas un tanto más precavidas que lo conciben como una estrategia de dominación cultural. De cualquier manera, la comprensión que se tenga del patrimonio, depende en gran medida, de cómo se disciernan las relaciones entre las diversas instancias sociales y la lógica del lugar; si bien el patrimonio histórico posee variadas cualidades, como expresión estética, como objeto del pasado o centro de la política, estas, en su gran mayoría, llevan a preguntarse por la manera cómo las sociedades adquieren ciertas relaciones con el espacio. Las discusiones en torno al Patrimonio Histórico obedecen no sólo al reconocimiento histórico y social de lo que es digno de ser recordado en las memorias nacionales, sino también a la legitimación de algunos lugares, objetos materiales y símbolos inscritos en un contexto especifico que pasan por relaciones de fuerza.

\section{Referencias}

Anderson, B. (1983). Comunidades imaginadas: reflexiones sobre los orígenes y difusión del nacionalismo.

Berger, P. \& Luckmann, T. (2011). La construcción social de la realidad. Buenos Aires: Editorial Amorrortu.

Bourdieu, P. (1999). Efectos de lugar en La miseria del mundo. México: Fondo de cultura económica. 
Bustos, M. (2010). El patrimonio y la lucha por los sentidos en el distrito capital. Revista calle 14 (4).

Chavarro, C. \& Llano, F. (2010) El héroe, el lujo y la precariedad: patrimonio histórico en Bogotá [1880-1950]. Universidad La Gran Colombia, Facultad de Ciencias de la Educación.

Cortázar R (1938) Monumentos, estatuas, bustos, medallones y placas conmemorativas existentes en Bogotá en 1938 editorial selecta

Deas, M. (1993). Del poder y la gramática y otros ensayos sobre historia política y literatura colombiana; Miguel Antonio Caro y sus amigos: gramática y poder. Colombia: Tercer mundo editores.

García, N. (1994). El porvenir del pasado. En Culturas híbridas. Estrategias para entrar y salir de la modernidad, pp. 149-190. México, Fondo de Cultura económica

Gergen, K. \& Gergen, M. (2011). Reflexiones sobre la construcción social. España: Editorial Paidós

Hobsbawm, E. (1997). Naciones y nacionalismos desde 1780. Barcelona: Editorial Crítica.

Llano, F. (2019) La superación del mito de la Atenas suramericana: los cafés como espacios de la producción cultural (Bogotá 1880-1930) en: Empreu aquest identificador per citar o enllaçar aquesta tesi: http://hdl.handle.net/10803/667757

Llano, M. (1994). Plaza de Bolívar la manzana de la discordia en: Arturo, J. (Comp.) Pobladores urbanos. Colombia: TM editores ICANH

López de la Roche F.(2000). Multiculturalismo, viejas y nuevas memorias y construcción de identidades abiertas, dialógicas y experimentales en: museo, memoria y nación, misión de los museos nacionales para los ciudadanos del futuro; Gonzalo Sánchez Gómez, María Emma wills Obregón compiladores

Lourés, M. (2001). Del concepto de monumento histórico al de patrimonio cultural. Revista de Ciencias Sociales. Recuperado desde: 


\section{<http://www.redalyc.org/articulo.oa?id=15309411> ISSN 0482-5276}

Martínez, F. (2000). ¿Cómo representar a Colombia? De las exposiciones universales a la exposición del centenario 1851- 1910. En: Sánchez, G. \& Wills, M. (comp.) Museo, memoria y nación, misión de los museos nacionales para los ciudadanos del futuro. Colombia: Ministerio de Cultura.

Ovalle, A. (2013). Memoria y monumentos en la celebración del centenario. Revista de memoria 4

Serna A. (2001) Próceres, textos y monumentos: culturas urbanas, discursos escolares y formas de la historia: Bogotá 1938- 1991. Colombia: Editorial Universidad del bosque Facultad de educación.

Serna, A. (2010) la invención de unos pasados: Esbozo para una historia social del patrimonio histórico colombiano en Todos somos Colombia

Van der Hammen, M. Lulle Thierre y Palacio Dolly. 2009 La construcción del patrimonio como lugar: Un estudio de caso en Bogotá. Revista Antipoda. Recuperado desde: http://antipoda.uniandes.edu.co/view.php/126/index.php?id=126

Vignolo P, (2013) ¿quién gobierna la ciudad de los muertos? Políticas de la memoria y desarrollo urbano en Bogotá. Revista memoria y sociedad Universidad Javeriana

Viviescas, F. (1994). El problema cultural de la ciudad colombiana y la arquitectura. En: La ciudad como bien cultural. Memorias del seminario. Colcultura. Santafé de Bogotá.

Zambrano, F. (2002). De la Atenas suramericana a la Bogotá moderna. La construcción de la cultura ciudadana en Bogotá. Revista de estudios sociales N11. 